\title{
VARIABILITY OF AIR VOIDS AND MECHANISTIC PROPERTIES OF PLANT PRODUCED ASPHALT MIXTURES
}

\author{
By
}

\author{
Louay N. Mohammad ${ }^{1}$ Ph.D. Corresponding Author \\ Zhong $\mathrm{Wu}^{2}$, Ph.D., P.E. \\ Chenggang Zhang ${ }^{3}$ \\ Mohammad J. Khattak ${ }^{4}$, Ph.D. \\ Chris Abadie ${ }^{5}$ P.E.
}

\author{
Louisiana Transportation Research Center \\ 4101 Gourrier Lane \\ Baton Rouge, LA 70808 \\ Phone: (225) 767-9126 \\ Fax: (225) 767-9108 \\ E-mail: louaym@1su.edu
}

\section{Submitted to: \\ $83^{\text {th }}$ Transportation Research Board Annual Meeting \\ January 11-15, 2004 \\ Washington, D.C.}

${ }^{1}$ Associate Professor, Depart. of Civil and Environmental Engineering and Louisiana Transportation Research Center, Louisiana State University, 4101 Gourrier Ave, Baton Rouge, LA 70808.

${ }^{2}$ Research Associate, Louisiana Transportation Research Center, 4101 Gourrier Ave, Baton Rouge, LA 70808

${ }^{3}$ Graduate Research Assistant, Louisiana Transportation Research Center, 4101 Gourrier Ave, Baton Rouge, LA 70808

${ }^{4}$ Assistant Professor, Depart. of Civil Engineering University of Louisiana at Lafayette, PO Box 42991, Lafayette LA 70504.

${ }^{5}$ Material Research Manager, Louisiana Transportation Research Center, 4101 Gourrier Ave, Baton Rouge, LA 70808 


\begin{abstract}
This paper presents the results of a laboratory and field evaluation of the variability of physical and mechanistic properties of plant produced asphalt mixtures. Three asphalt mixtures from two overlay rehabilitation projects were selected. Comparison analyses were conducted on density measurements between two laboratory (AASHTO T-166 and ASTM D6752-02, or CoreLok) and one in-situ test (PQI) methods. In addition, two laboratory mechanistic tests: Indirect tensile (IDT) strength and Frequency sweep at constant height (FSCH) tests, and two field non-destructive tests using falling weight deflectometer (FWD) and light weight falling weight deflectometer (LFWD) were performed to characterize the variability of the plant produced mixtures evaluated in this study. Superpave Gyratory Compactor (SGC) samples and field cores were used in the laboratory testing program. A strong correlation was observed between the two laboratory bulk specific gravity test methods: the AASHTO T-166 and the CoreLok. The IDT strengths of SGC samples were found higher than those of field cores. A good correlation was found between the complex shear moduli of SGC samples and field cores. Field test results indicated that LFWD test may be used as an alternative for the FWD test in pavement structure evaluation.
\end{abstract}

KEYWORDS: Asphalt, mixture, air void, core, SGC, IDT, FSCH, FWD, LFWD, PQI, CoreLok 


\section{VARIABILITY OF AIR VOIDS AND MECHANISTIC PROPERTIES OF PLANT PRODUCED ASPHALT MIXTURES}

\section{INTRODUCTION}

The performance of asphalt pavements is influenced by two primary factors: properly designed mixture and consistent plant production and field compaction. Neither of these factors alone can assure satisfactory pavement life $[1,2]$.

To obtain a properly designed asphalt mixture, the fundamental engineering properties of asphalt mixture must relate to its field performance. However, relating mixture's laboratory engineering properties to its field behavior is a not simple task. Currently, there are no commonly accepted relationships between laboratory mechanical tests and mixture field performance. Daniel and et al. [3] performed a study on comparison of laboratory and field stiffness tests. Five test methods were selected in that study: three laboratory tests - creep compliance, complex modulus and impact resonance method, and two field non-destructive tests (NDTs) - falling weight deflectometer and surface wave method. The results of the study indicated that the laboratory stiffness of asphalt mixtures may be predicted from the field NDT testing using a log-log linear relationship between frequency and stiffness. Brown and Foo [4] conducted a study on evaluating the variability of resilient modulus (Mr) of laboratory samples and field cores. They reported that (1) the resilient modulus values were influenced by the magnitude of the applied load; (2) the variation of the resilient modulus is higher in the field cores relative to the laboratory samples. They attributed this variation to the variable dimensions of cores influenced by the method of coring. However no direct comparisons were made on mixtures with similar density values.

The Superpave Gyratory Compactor (SGC) was evaluated, among other compactors, by 
the SHRP research team [5,6,7], and recommended as a part of the Superpave mixture design method. A recent research conducted by Baladi and Crince [8] studied the design parameters and engineering characteristics of the conventional and the Superpave mixtures. All mixtures were obtained from the paver's hopper and compacted in laboratory using the SGC. After construction was completed, the falling weight deflectometer tests were conducted and the cores were extracted. Both laboratory compacted samples and field cores were tested under indirect tensile cyclic loading at $20^{\circ} \mathrm{C}$. They reported that a good power-law relationship exists between the backcalculated asphalt layer modulus and the core modulus. However, in their study no direct comparison was made between field cores and laboratory compacted samples.

Researches have shown that pavement density is related to pavement durability and distresses (e.g. rutting, mixture segregation, etc.) [9]. Current method of measuring pavement density in the quality assurance process is performed by securing field cores at several locations and conducting air voids tests in the laboratory as specified in AASHTO T-269 "Standard Method of Test for Percent Air Voids in Compacted Dense and Open Bituminous Paving Mixtures". This process is considered costly, laborious and destructive. Alternative methods for measuring in-place pavement density include nuclear based and non-nuclear based test devices. The nuclear-based devices tend to have problems associated with licensing, equipment handling, storage and accuracy of measurement. Hence, the non-nuclear based density devices are becoming attractive to many state highway agencies as the alternative to nuclear density gauges. The pavement quality indicator (PQI), manufactured by the TransTech, Inc., is a newlydeveloped non-nuclear based density device. The PQI uses principles of electrical impedance and the dielectric constants of materials to determine the densities of asphalt pavements [10]. Several studies $[2,10]$ in literature reported to have used a PQI device in pavement density 
measurements. However, the density measured by PQI appeared to be repeatable but did not correlate well with the densities measured by laboratory devices.

This paper presents the results of a laboratory/field evaluation study, conducted to evaluate the physical and mechanistic variability of plant produced mixtures on two field construction projects.

\section{OBJECTIVE AND SCOPE}

The objectives of this project include (1) evaluation of the variability of pavement density due to mixture production; (2) comparison of air void measurements between laboratory and field test methods; (3) fundamental characterization of SGC samples and field cores; (4) assessment of the in-situ test measurements.

Laboratory density measurement methods used in this study included the AASHTO T166 "Standard Specification for Bulk Specific Gravity of Compacted Bituminous Mixtures Using Saturated Surface-Dry Specimens" and the ASTM D6752-02 "Standard Test Method for Bulk Specific Gravity and Density of Compacted Bituminous Mixtures Using Automatic Vacuum Sealing Method", also known as "CoreLok". The field pavement density was measured using a PQI Model 301 device. Mechanistic evaluation on laboratory samples and field cores included the indirect tensile strength and strain (ITS) and the frequency sweep at constant height (FSCH) tests. In addition, two in-situ test methods were performed: a light falling weight deflectometer (LFWD) and a falling weight deflectometer (FWD).

\section{PROJECT IDENTIFICATION}


The selection of two overlay rehabilitation projects was coordinated with the Louisiana Department of Transportation and Development (LADOTD) construction and research personnel. The first project is located in Acadia Parish on Interstate Highway I-10 near the community of Egan, hereafter designated as I-10 Egan. The second construction project is located in Calcasieu Parish also on F10 near the city of Vinton, hereafter designated as F10 Vinton. The pavement structure of F10 Egan project consists of $50 \mathrm{~mm}$ wearing course $(12.5 \mathrm{~mm}$ Superpave mixture) and $188 \mathrm{~mm}$ binder (25mm Superpave mixture) over $250 \mathrm{~mm}$ rubblized Portland cement concrete (PCC) base layer. The pavement structure of I-10 Vinton project consists of $50 \mathrm{~mm}$ wearing course layer (12.5mm SMA mixture) and a $176 \mathrm{~mm}$-binder course layer (25mm Superpave) over $250 \mathrm{~mm}$ PCC base layer. The subgrade for both projects consisted of a silty clay (AASHTO A-6 soil classification) soil type.

Hot Mix Asphalt (HMA) mixtures from two layers of the I-10 Egan project (wearing and binder courses) and wearing course mixture from the I-10 Vinton project were considered in this study. To evaluate production variability of physical and mechanistic properties, six test sections were selected from the F10 Egan project. Each section represents a sublot quantity of 1,000 tons continuous plant produced HMA. However, only one section from the F10 Vinton project was evaluated due to difficulty in obtaining sufficient sections. The loose HMA mixtures were secured directly from the paver, between the auger and screed end plate. . These HMA mixtures were subsequently transported to a nearby mobile laboratory and compacted to the desired density and geometry. The laboratory produced samples were compacted to a density similar to those achieved in the field for each test sections.

\section{PLANT PRODUCED ASPHALT MIXTURES}


Table 1(a) presents the job mix formula (JMF) for the three plant produced asphalt mixtures evaluated in this study. Both F10 Egan wearing and binder Superpave mixtures are designed for high volume roads as per the Louisiana Standard Specifications for Roads and Bridges (2000 Edition) [11] at a compaction gyration number of $\mathrm{N}_{\mathrm{ini}}, \mathrm{N}_{\mathrm{des}}$, and $\mathrm{N}_{\max }$ of $9,125,205$ gyrations, respectively. The I-10 Vinton wearing course mixture is a typical high-volume Stone Matrix Asphalt (SMA) mixture used in Louisiana [11].

Several loose HMA mixture samples obtained at each test sections were extracted in the laboratory for asphalt mixture composition (binder content and gradation) analysis. Table 1(b) presents the changes in mixture composition away from the JMFs at each test section. The

changes in mixture composition were computed by subtracting the measured values (in percentage) from those in the JMFs. The positive value in the table represents that the measured value is greater than that in the JMF, and vice versa. As shown in Table 1(b), the majority test sections in I-10 Egan projects had higher binder contents than the design value, except for Section 1 (S1) of H10 Egan binder course. The changes in binder content for I-10 Egan projects varied from $-0.1 \%$ to $0.6 \%$ for the binder course mixture and from 0.8 to 1.0 percent for the wearing course mixture. The test section in F10 Vinton SMA mixture had a 0.4 percent lower binder content than the JMF.

\section{EXPERIMENTAL DESIGN}

Field Non-Destructive Tests

In-situ properties of asphalt mixtures in this study were characterized through comparisons of test results from three field tests - PQI, FWD and LFWD.

Pavement Quality Indicator (PQI) 
The PQI is a non-nuclear density measurement device. The device has a circular base plate housing a transmitter at the center that emits an electric flow into the asphalt materials [12]. Density values are determined on the basis of the principle that the changes in dielectric constants of the mixture are proportional to the level of compaction or density. Many variables affect the measurements of PQI, such as moisture content, pavement temperature, aggregate size and source. A PQI Model 301 device was used in this study.

\section{Falling Weight Deflectometer (FWD)}

The falling weight deflectometer (FWD) test is perhaps the most popular field non-destructive test (NDT) used in pavement evaluation and management system. The equipment uses a weight that is lifted to a given height on a guide system, and then dropped onto a $300 \mathrm{~mm}$ circular load plate, with a thin rubber pad mounted underneath. Normally, seven sensors at a certain configuration spacing are used to measure the surface deflections in a FWD test. A Dynatest 800 model FWD device utilizing seven sensors was used in this study. The sensor configuration selected was $0,200,300,600,900,1200$, and 1800mm and two load levels of $40 \mathrm{KN}(9,000 \mathrm{lbs})$ and $67 \mathrm{KN}(15,000 \mathrm{lbs})$ were used for each test.

\section{Light Falling Weight Deflectometer (LFWD)}

Another field NDT test included in this study is the light falling weight deflectometer (LFWD) test. The LFWD is a portable device, which is designed for estimating the bearing capacity and compaction of the soil ground. A PRIMA-100 LFWD device, manufactured by the Carl Bro Company, Denmark, was selected for testing. The PRIMA-100 device consists of a $10 \mathrm{~kg}$ (22 lbs) drop weight that falls freely onto a loading plate $(200 \mathrm{~mm}$ in diameter) producing a load pulse, and one geophone sensor to measure the center surface deflection. The output from the 
test is called the dynamic deformation modulus, which is calculated from the center deflection measured based on the Boussineq elastic half space theory.

Figure 1 presents the field test layout and core locations. There are fifteen test points at each test section. The LFWD and FWD tests were conducted on each fifteen points. Five LFWD readings were taken at each of the fifteen points and averaged for each point. However, five PQI readings were collected for each point resulting in a 75 density measurements $(5 \times 15)$ at each test section. It should be noted that both wearing and binder course test sections have similar test locations. A GPS (global positioning system) receiver was used to establish these locations.

\section{Laboratory Mixture Characterization}

SGC samples and field cores in this study were characterized in the laboratory through conducting of air void measurements, ITS and FSCH tests. A brief description of each test method is provided as follows.

\section{Air Void Measurements}

The bulk specific gravities of field cores were measured using both AASHTO T166 and ASTM D6752-02 (so-called "CoreLok") test methods. The bulk specific gravities of SGC samples were determined by the AASHTO T-166 method. The percent air voids of compacted samples were computed as follow:

$$
\text { Air Void, \% = } 100 \text { (1- Gmb/Gmm) }
$$

Where,

$$
\begin{aligned}
& \text { Gmm - Theoretical Maximum Specific Gravity, and } \\
& \text { Gmb - Bulk Specific Gravity. }
\end{aligned}
$$


In this study, the total number of field cores and SGC samples used in the density measurements were 72 and 45 , respectively.

\section{Indirect Tensile Strength and Strain Test Results}

This test was conducted at $25^{\circ} \mathrm{C}$ according the AASHTO T245. A cylindrical specimen is loaded to failure at a deformation rate of $50.8 \mathrm{~mm} / \mathrm{min}$ using a MTS machine. The IDT strength was used in the analysis. In this study, one SGC sample and one field core from each test section were selected to perform the IDT test.

\section{Frequency Sweep at Constant Height (FSCH)}

The FSCH test is conducted according to AASHTO TP7 Procedure E at two temperatures. It is a strain controlled test that applies a shear stress to a cylindrical test specimen to produce a shear strain with a peak amplitude of $0.0005 \mathrm{~mm} / \mathrm{mm}$. A sinusoidal shear loading is applied at a sequence of 10 frequencies $(10,5,2,1,0.5,0.2,0.1,0.05,0.02,0.01 \mathrm{~Hz})$ to produce a sinusoidal shear strain. The properties obtained from this test were dynamic shear modulus and phase angle.

Two SGC samples and two field cores, selected from each test section, were used in the FSCH tests at two test temperatures: 48 and $60^{\circ} \mathrm{C}$. A total of thirty SGC samples and thirty field cores were tested in this study.

\section{DISCUSSION OF TEST RESULTS}

\section{Field and Laboratory Air Void Measurements}

Table 2 presents a summary of air voids of the field cores for the three mixture types considered. Two laboratory and one in-situ test methods were used in the air void measurements. For the AASHTO T166 method, the average percent air void of the I-10 Egan binder course, I-10 Egan wearing course and I10 Vinton wearing course was 5.5, 6.4 and 7.5, respectively. The CoreLok method indicated an average percent air void for the I-10 Egan binder course, I-10 Egan wearing 
course, and I-10 Vinton wearing course of 5.9, 6.7, and 8.0, respectively. The average in-situ air void as measured by the PQI device for the F10 Egan binder course, I-10 Egan wearing course, and I-10 Vinton wearing course was 5.2, 6.6, and 4.9, respectively.

\section{Comparison of Air Void Measurement Methods}

A good correlation was observed between air voids measured using AASHTO T-166 and CoreLok methods, Figure 2(a). Their relationship has the following linear form:

$$
\text { Air Void } \%_{(\text {CoreLoK })}=1.054\left[\text { Air Void \% }(\text { AASHTO T-166) }] \quad\left(R^{2}=0.92\right)\right.
$$

In general, the CoreLok measured air void was about 0.5 percent higher than the one determined from the AASHTO T-166 method. As noted in table 2, variations from CoreLok were slightly higher than those of the AASHTO T-166. It is noted that the correlation between the PQI measured air voids and the air voids measured by either the CoreLok or the AASHTO T166 method were not very strong $\left(\mathrm{R}^{2}=0.5\right)$, Figure $2(\mathrm{~b})$. The PQI air voids measurements, as indicated in table 2, were lower for the I-10 Vinton SMA mixture than the Corelok and AASHTO T-166 air void measurements. Similar observations were reported by Prowell et al. [2] and Hausman et al. [10].

\section{Variation of Air Void Within Section}

The air voids measured by the AASHTO 166 method were used to analyze the density variation within each test section. The standard deviation within each test section varied from 0.5 to 1.7 percent, 0.2 to 1.6 percent, and 0.6 percent for the F10 Egan binder course, F10 Egan wearing course and F10 Vinton wearing course, respectively, Table 2. For the Egan binder course, the standard deviation for a test section showed an increasing trend as the average air voids increased in that section. The highest percent coefficient of variation was found to be 24.1, 24.5, and 7.8 percent within a test section for the F10 Egan binder course, I-10 Egan wearing course 
and I-10 Vinton wearing course, respectively. It was observed that the binder course mixture had the highest variation as measured by all three methods, followed by the I-10 Egan wearing course and I-10 Vinton Wearing course mixtures, respectively.

\section{Variation of Air Void Between Sections}

The average air voids varied significantly between six test sections for both the I-10 Egan wearing and binder course mixtures. The average air voids measured by the AASHTO T-166 method ranged from 3.6 to 7.1 percent for the I-10 Egan binder course and from 4.6 to 8.0 percent for the I-10 Egan wearing course, respectively, Table 2. The variation of air voids between test sections may be attributed both to the changes in mixture composition (Table $1 \mathrm{~b}$ ) and to the non-homogeneous paving and compaction.

\section{Laboratory Mechanical Tests}

\section{Indirect Tensile Strength and Strain Test Results}

Figure 3 presents the variation of the indirect tensile (IDT) strength for the test sections considered. The IDT strength of the I-10 Egan binder course layer possessed the highest variability, followed by the I-10 Egan wearing course. The I-10 Vinton section with SMA

mixture had the lowest variation, Figure 3. The core and SGC samples had similar IDT variations, except for the SMA mixture where the cores had significantly lower percent coefficient of variation than SGC samples. This ranking is similar to the air voids variation of these mixtures, Table 2. The IDT strengths of the SGC samples were higher than those of the cores except for Section 1 of the I-10 Egan binder layer, Figure 3. This exception may be attributed to the significantly low air void in the SGC sample used. 
Figure 4 presents the variations in IDT strengths with air voids for the F10 Egan binder and wearing course mixtures. The IDT strengths of field cores had a fairly good linear relationship with air voids, with the correlation coefficient $\left(\mathrm{R}^{2}\right.$-values) of 0.93 and 0.73 for the Egan binder and wearing course mixtures, respectively. As expected, the IDT strength decreased as the air void of cores increased. The same general linear trend between the IDT strength and the air void was also observed for SGC samples. $\mathrm{R}^{2}$-value of the I-10 Egan binder SGC samples was 0.60. However, a low correlation coefficient was found for the Egan wearing SGC samples. In summary, the IDT strengths of field cores showed better correlations to the air voids than SGC samples. This may be attributed to different air void distribution between field cores and SGC samples. Also, as previously stated, as air voids increase, the IDT strength decreases.

\section{Frequency Sweep at Constant Height (FSCH)}

Table 3 presents a summary of the FSCH tests for both field cores and SGC samples at two test temperatures of 48 and $60{ }^{\circ} \mathrm{C}$. Figure 5 shows the variation of the complex shear modulus of $\mathrm{G}^{*}$ at $10 \mathrm{~Hz}$ for all test sections considered. As expected, the $\mathrm{G}^{*}$ value of an asphalt mixture decreases as the temperature increases and the loading frequency decreases. In addition, the phase angle decreased with an increase in temperature at all loading frequencies. The aggregate effects begin to dominate the mixture response with an increase in temperature, thereby causing the phase angle to decrease and the mixture to have more elastic response. For the mixtures considered, the field cores yielded lower $\mathrm{G}^{*}$ than the SGC samples at both 48 and $60{ }^{\circ} \mathrm{C}$. This is consistent with the results from the IDT strength test. The highest difference of $\mathrm{G}^{*}$ values between the SGC samples and field cores was observed in Section 4 of the H10 Egan binder course tested at $48{ }^{\circ} \mathrm{C}$ and Section 6 of the Egan wearing course tested at $60{ }^{\circ} \mathrm{C}$, Figure 5 . 
It is shown in Figure 5 that the variations of $\mathrm{G}^{*}$ values of the I-10 Egan binder and wearing course were found similar to each other. The I-10 Vinton section with the SMA mixture possessed the lowest variability. In general, the overall variations in $\mathrm{G}^{*}$ measurement were well within the test method variations [15]. The I-10 Vinton SMA mixture showed the highest average complex shear moduli $\left(\mathrm{G}^{*}\right)$ among the three mixtures considered, at all test frequencies and temperatures, and for both SGC samples and field cores. No statistical difference in the G* of field cores were observed between the I-10 Egan binder and wearing course Superpave mixtures. However, the average $\mathrm{G}^{*}$ values of the I-10 Egan wearing SGC samples were found to be higher than those of I-10 Egan binder SGC samples at different frequencies and both temperatures.

Figure 6(a) presents the relationship between the average $\mathrm{G}^{*}$ at $10 \mathrm{~Hz}$ at two temperatures for both SGC samples and field cores of the three mixtures evaluated. It is observed that the rate of change of $\mathrm{G}^{*}$ at $10 \mathrm{~Hz}$ at the two test temperatures were very similar for both SGC samples and field cores. A slightly higher changing rate was found for the I-10 Vinton SGC samples. A good correlation was observed between the $\mathrm{G}^{*}$ of the cores and SGC samples, Figure 6(b). The following regression equations were obtained using the FSCH test results of the three mixtures.

$$
\begin{array}{ll}
\mathrm{G}^{*}(\mathrm{SGC})_{10 \mathrm{HZ}}=1.5664 \mathrm{G}^{*}(\text { core })_{10 \mathrm{HZ}} & \left(\mathrm{R}^{2}=0.88\right) \\
\mathrm{G}^{*}(\mathrm{SGC})_{0.1 \mathrm{HZ}}=1.4673 \mathrm{G}^{*}(\text { core })_{0.1 \mathrm{HZ}} & \left(\mathrm{R}^{2}=0.78\right)
\end{array}
$$

In general, the $\mathrm{G}^{*}(\mathrm{SGC})$ was 56 and 47 percent higher than the $\mathrm{G}^{*}$ (core) at the loading frequencies of $10 \mathrm{~Hz}$ and $0.1 \mathrm{~Hz}$, respectively. 


\section{Field NDT Testing}

Two NDT tests - LFWD and FWD were performed on each test section in this study. Figure 7 presents the FWD deflection variations for I-10 Egan wearing and binder course layers. To minimize variations in the applied load, the deflections have all been normalized to a standard contact pressure of $600 \mathrm{kPa}$. Deflections d1 (center load plate), d7 (1,500 mm from load), and deflection difference d1-d6 (d6 at $900 \mathrm{~mm}$ from load) can be interpreted as indicators of overall pavement condition, capping and subgrade condition, and asphalt layer condition, respectively $[13,14]$. It is noted that Section 3 of the F10 Egan project had the weakest pavement structure as indicated by high $\mathrm{d} 1$ deflections, followed by Section 4 , Figure 7 . The $\mathrm{d} 7$ in sections 3 and 4 also showed higher deflection values than other sections indicating that the weakness of pavement structures could be attributed to a weak subgrade. A similar variation was found among deflections of d1-d6.

Figure 8 presents the results of LFWD measurements for all test sections considered. The variation of the LFWD deformation modulus $\left(\mathrm{E}_{\mathrm{LFWD}}\right)$ was found higher in the I-10 Egan wearing course than in the I-10 Egan binder course. The I-10 Vinton, with only one section, possessed the lowest variation among the three projects, Figure 8. As shown in Figure 9, good correlations were observed between $\mathrm{E}_{\mathrm{FWD}}$ and deflections of $\mathrm{d} 1$ and $\mathrm{d} 1 \mathrm{~d}$ - 6 for both the $\mathrm{F} 10$ Egan binder and wearing course layers. The $\mathrm{R}^{2}$-values between $\mathrm{E}_{\mathrm{LFWD}}$ and $\mathrm{d} 1$ were 0.76 and 0.82 for the I-10 Egan binder and wearing course, respectively. Similar $\mathrm{R}^{2}$-values were obtained between $\mathrm{E}_{\mathrm{LFWD}}$ and d1-d6, Figure 9.

Since both $\mathrm{d} 1$ and $\mathrm{d} 1-\mathrm{d} 6$ are indicators of asphalt pavement structure condition, this observation indicates that LFWD test may be used as an alternative for FWD testing in pavement structure evaluation. 


\section{SUMMARY AND CONCLUSIONS}

Three Hot Mix Asphalt mixture types from two overlay rehabilitation projects were evaluated in this study. Comparative analyses on density measurements were conducted between two laboratory and one in-situ test methods. Two laboratory mechanistic tests and two field NDT tests were performed to characterize the variability of plant produced asphalt mixtures. The following observations and findings can be drawn from this study:

- A strong correlation was found between air voids measured using the AASHTO T-166 and the ASTM D6752-02 (CoreLok) bulk specific gravity methods. In general, the CoreLok measured air void was about 0.5 percent higher than the air void determined from the AASHTO 166 method.

- It was observed that the correlation between the PQI measured air voids and the air voids measured by either the CoreLok or the AASHTO T-166 method was not very strong. The PQI air voids measurements were lower for the I-10 Vinton SMA mixture than both CoreLok and AASHTO T-166 air void measurements.

- Variations of air voids within test sections were primarily attributed to construction variation. Variations of air voids between test sections were found due to changes in plant produced asphalt mixtures and construction variation.

- The IDT strengths of SGC samples were found higher than that of field cores. In addition, the IDT strengths of field cores showed better correlations to the air voids than SGC samples. This may be attributed to different air void distribution between field cores and SGC samples. 
- A good correlation was found between the complex shear moduli of SGC samples and field cores. In general, SGC samples possessed about 50 percent higher of the complex shear moduli than field cores.

- The deformation modulus from LFWD tests had a linear relationship with deflections of d1 and d1-d6 of the FWD tests. Thus, LFWD test may be used as an alternative for the FWD test in the pavement structure evaluation

\section{ACKNOWLEDGEMENT}

The research work reported in this paper was sponsored by LADOTD and FHWA through the Louisiana Transportation Research Center under contract number 02-3B. The authors would like to express their appreciation to all those who provided valuable help in the conduct of this project.

\section{References}

1. Hughes, C.S. NCHRP Synthesis of Highway Practice 152: Compaction of Asphalt Pavement. TRB, National Research Council, Washington, D.C., 1989.

2. Prowell, B.D. and Dudley, M.C. Evaluation of Measurement Techniques for Asphalt Pavement Density and Permeability. Transportation Research Board 1789, TRB National Research Council, Washington, D.C., 2002.

3. Daniel, J.S. and R.Y. Kim, Relationships Among Rate-Dependent Stiffnesses of Asphalt Concrete Using Laboratory and Field Test Methods, Transportation Research Board 1638, TRB National Research Council, Washington, D.C., 1998.

4. Brown, E.R. and K.Y. Foo, Evaluation of Variability of in Resilient Modulus Test Results ((ASTM D 41 23), NCAT Report No. 91-6, October 1989. 
5. Button J.W., Dallas N. Little, Vidyasagar J. and Olga J. P., Correlation of Selected Laboratory Compaction Methods with Field Compaction, Transportation Research Board 1454, TRB National Research Council, Washington, D.C., 1994.

6. Consuegra, A., DallasN. L., Harold V. Q. and James B., Comparative Evaluation of Laboratory Compaction Devices Based on Their Ability to Produce Mixtures with Engineering Properties Similar to Those Produced in the Field, Transportation Research Board 1228, TRB National Research Council, Washington, D.C., 1989.

7. SHRP-A-415 Permanent Deformation Response of Asphalt Aggregate Mixes. University of California, Berkeley, Strategic Highway Research Program, National Research Council. 1994.

8. Baladi, G. Y. and Jonathan E. Crince, The Engineering Characteristics of Michigan Asphalt Mixture, Final Report No. MDOT-PRCE-MSU-1999-110, submitted to Michigan Department of Transportation (MDOT), December 27, 1999.

9. Chang C. and et al. Detecting Segregation in Bituminous Pavements. Transportation Research Board 1813, TRB National Research Council, Washington, D.C., 2002.

10. Hausman , J. and et al. Analysis of TransTech Model 300 Pavement Quality Indicator Laboratory and field Studies for Determining Asphalt Pavement Density. Transportation Research Board 1813, TRB National Research Council, Washington, D.C., 2002.

11. "Louisiana Standard Specifications for Roads and Bridges," State of Louisiana, Department of Transportation and Development, Baton Rouge, 2000 Edition.

12. Pavement Quality Indicator Model 301 Operator's Handbook. TranTech System, Inc. 2001.

13. Collop, A.C. and et al. Assessing Variability of In Situ Pavement Material Stiffness Moduli. Journal of Transportation Engineering, January/February 2001 
14. Brown, S.F. and et al. Development of an analytical method for the structural evaluation of pavements. $2^{\text {nd }}$ Int. Conf. On Bearing Capacity of Roads and airfields, WDM, Bristol, U.K., 1986.

15. Anderson, R. and McGennis, R., Ruggedness Evaluation of the Shear Frequency Sweep Test for Determining the Shear Modulus of Asphalt Mixtures, Annual meeting of Association of Asphalt Paving Technologists, 2003. 


\section{List of Tables}

Table 1. Job Mix formula and mixture production variations

Table 2. Summary of air void measurement results

Table 3. Summary of complex shear modulus results

\section{List of Figures}

Figure 1. Field test layout and roadway core locations

Figure 2. Air void relationship between test methods

Figure 3. Indirect tensile strength test results

Figure 4. Relationship between IDT strengths and air voids

Figure 5. Results of complex shear modulus $\left(\mathrm{G}^{*}{ }_{10 \mathrm{~Hz}}\right)$ at two test temperatures

Figure 6. (a) Relationship between complex shear modulus $\left(\mathrm{G}^{*}{ }_{10 \mathrm{~Hz}}\right)$ and temperatures

(b) Relationship between complex shear moduli of SGC samples and field cores

Figure 7. Results of FWD deflection measurements

Figure 8. Results of LFWD measurements

Figure 9. Relationship between FWD deflections and LFWD deformation modulus 
Table 1(a). Job Mix Formula of Asphalt Mixtures

\begin{tabular}{|c|c|c|c|}
\hline Mixture Name & $\begin{array}{c}\text { Egan Binder } \\
\text { Course }\end{array}$ & $\begin{array}{c}\text { Egan Wearing } \\
\text { Course }\end{array}$ & $\begin{array}{c}\text { Vinton Wearing } \\
\text { Course }\end{array}$ \\
\hline Mixture Type & $25 \mathrm{~mm}$ Superpave & 12.5mm Superpave & SMA \\
\hline Aggregate Type & Crushed limestone & Crushed limestone & $\begin{array}{c}\text { Crushed limestone } \\
\text { \&sandstone }\end{array}$ \\
\hline Asphalt Binder Type & PG 76-22M* & PG 76-22M* & PG 76-22M* \\
\hline Design Binder Content, \% & 4.0 & 5 & 6.0 \\
\hline Design Air Void, \% & 4.0 & 4.0 & 4.0 \\
\hline VMA, \% & 12.8 & 14.5 & 16.6 \\
\hline VFA, $\%$ & 69.5 & 72 & 76 \\
\hline U.S. (Metric) Sieve & \multicolumn{3}{|c|}{ Gradation, (\% passing) } \\
\hline $11 / 2$ inch $(37.5 \mathrm{~mm})$ & 100 & 100 & 100 \\
\hline 1 inch $(25 \mathrm{~mm})$ & 96 & 100 & 100 \\
\hline $3 / 4$ inch $(19 \mathrm{~mm})$ & 87 & 100 & 100 \\
\hline $1 / 2$ inch $(12.5 \mathrm{~mm})$ & 68 & 98 & 93 \\
\hline ? inch $(9.5 \mathrm{~mm})$ & 59 & 89 & 71 \\
\hline No. $4(4.75 \mathrm{~mm})$ & 35 & 50 & 30 \\
\hline No. $8(2.36 \mathrm{~mm})$ & 23 & 29 & 20 \\
\hline No. $16(1.18 \mathrm{~mm})$ & 17 & 19 & - \\
\hline No. $30(0.6 \mathrm{~mm})$ & 13 & 13 & 15 \\
\hline No. $50(0.3 \mathrm{~mm})$ & 7 & 10 & 12 \\
\hline No. $100(0.15 \mathrm{~mm})$ & 4 & - & - \\
\hline No. $200(0.075 \mathrm{~mm})$ & 3.6 & 6.5 & 8 \\
\hline
\end{tabular}

* M means polymer-modified asphalt binder.

\section{Table 1(b). Production variation of plant produced asphalt mixtures}

\begin{tabular}{|c|c|c|c|c|c|c|c|c|c|c|c|c|c|c|}
\hline \multirow{2}{*}{\multicolumn{2}{|c|}{ Test Sections }} & \multicolumn{6}{|c|}{ I-10 Egan Binder Course } & \multicolumn{6}{|c|}{ I-10 Egan Wearing Course } & \multirow{2}{*}{$\begin{array}{c}\begin{array}{c}\text { Vinton } \\
\text { Wearing }\end{array} \\
\text { S1 } \\
\end{array}$} \\
\hline & & S1 & $\mathrm{S} 2$ & S3 & S4 & S5 & S6 & S1 & S2 & $\mathrm{S} 3$ & S4 & S5 & S6 & \\
\hline \multicolumn{2}{|c|}{ Binder Content $(\%)$} & -0.1 & 0.6 & 0.3 & 0.4 & $\mathrm{n} / \mathrm{a}$ & $\mathrm{n} / \mathrm{a}$ & 0.8 & 0.8 & 1.0 & 1.0 & 0.8 & 0.8 & -0.4 \\
\hline \multirow{11}{*}{ 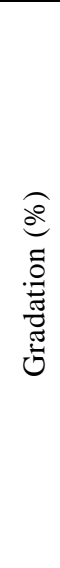 } & $1 "$ & 1.0 & 3.0 & 2.1 & 0.6 & $\mathrm{n} / \mathrm{a}$ & $\mathrm{n} / \mathrm{a}$ & 1 & 1 & 1 & 1 & 1 & 1 & 1 \\
\hline & $3 / 4 "$ & -1.0 & 3.0 & 3.6 & 2.1 & $\mathrm{n} / \mathrm{a}$ & $\mathrm{n} / \mathrm{a}$ & I & l & 1 & I & I & 1 & I \\
\hline & $1 / 2 "$ & -3.0 & 0.0 & -0.2 & -0.1 & $\mathrm{n} / \mathrm{a}$ & $\mathrm{n} / \mathrm{a}$ & 0.1 & 0.1 & 0.9 & 0.9 & 0.7 & 0.7 & 1.0 \\
\hline & $3 / 8^{\prime \prime}$ & -4.0 & -2.0 & -2.4 & -2.2 & $\mathrm{n} / \mathrm{a}$ & $\mathrm{n} / \mathrm{a}$ & -0.9 & -0.9 & 1.6 & 1.6 & 2.8 & 2.8 & -2.1 \\
\hline & No. 4 & -2.0 & 1.0 & -2.5 & -2.5 & $\mathrm{n} / \mathrm{a}$ & $\mathrm{n} / \mathrm{a}$ & -1.8 & -1.8 & 2.4 & 2.4 & 0.9 & 0.9 & 0.6 \\
\hline & No. 8 & -1.0 & 1.0 & -1.0 & -1.8 & $\mathrm{n} / \mathrm{a}$ & $\mathrm{n} / \mathrm{a}$ & -0.3 & -0.3 & 1.2 & 1.2 & 0.1 & 0.1 & -0.2 \\
\hline & No. 16 & 0.0 & 0.0 & -1.0 & -1.4 & $\mathrm{n} / \mathrm{a}$ & $\mathrm{n} / \mathrm{a}$ & 0 & 0 & 0.5 & 0.5 & 0.3 & 0.3 & 1 \\
\hline & No. 30 & 0.0 & 0.0 & -1.1 & -1.3 & $\mathrm{n} / \mathrm{a}$ & $\mathrm{n} / \mathrm{a}$ & 0.4 & 0.4 & 0.7 & 0.7 & 0.9 & 0.9 & -1.2 \\
\hline & No. 50 & 2.0 & 2.0 & 0.5 & 0.5 & $\mathrm{n} / \mathrm{a}$ & $\mathrm{n} / \mathrm{a}$ & 0.3 & 0.3 & 0.5 & 0.5 & 0.9 & 0.9 & 0.0 \\
\hline & No. 100 & 2.0 & 2.0 & 1.1 & 1.2 & $\mathrm{n} / \mathrm{a}$ & $\mathrm{n} / \mathrm{a}$ & 1 & 1 & 1 & 1 & 1 & 1 & 1 \\
\hline & No. 200 & 0.8 & 1.2 & 0.5 & 0.6 & $\mathrm{n} / \mathrm{a}$ & $\mathrm{n} / \mathrm{a}$ & 0.7 & 0.7 & 1.2 & 1.2 & 1.3 & 1.3 & -0.1 \\
\hline
\end{tabular}


Table 2. Summary of air void measurement results.

\begin{tabular}{|c|c|c|c|c|c|c|c|c|c|c|}
\hline \multirow{3}{*}{\multicolumn{2}{|c|}{$\begin{array}{c}\text { Project \& Test } \\
\text { Section }\end{array}$}} & \multicolumn{6}{|c|}{ Laboratory } & \multirow{2}{*}{\multicolumn{3}{|c|}{$\frac{\text { Field }}{\text { PQI }}$}} \\
\hline & & \multicolumn{3}{|c|}{ Conventional (T-166) } & \multicolumn{3}{|c|}{ CoreLok } & & & \\
\hline & & Void & STD & $\% \mathrm{CV}$ & Void & STD & $\% \mathrm{CV}$ & Void & STD & $\% \mathrm{CV}$ \\
\hline \multirow{9}{*}{$\begin{array}{c}\text { I-10 Egan } \\
\text { BC }\end{array}$} & S1 & 3.6 & 0.5 & 14.7 & 3.2 & 0.5 & 15.3 & 4.9 & 0.68 & 13.9 \\
\hline & S2 & 4.2 & 0.6 & 14.6 & 3.5 & 0.9 & 25.7 & 6.5 & 0.55 & 8.4 \\
\hline & S3 & 5.9 & 0.8 & 12.9 & 6.2 & 1.4 & 21.9 & 5.6 & 0.62 & 11.2 \\
\hline & S4 & 5.4 & 0.8 & 14.0 & 6.2 & 1.5 & 24.4 & 5.2 & 0.87 & 16.5 \\
\hline & S5 & 7.0 & 1.7 & 24.1 & 7.9 & 2.1 & 26.4 & 4.3 & 1.25 & 34.0 \\
\hline & S6 & 7.1 & 1.1 & 14.9 & 8.2 & 1.3 & 15.8 & 4.8 & 0.76 & 18.5 \\
\hline & Avg. & 5.5 & \multirow[t]{3}{*}{0.9} & \multirow[t]{3}{*}{15.9} & 5.9 & \multirow[t]{3}{*}{1.3} & \multirow[t]{3}{*}{21.6} & 5.2 & \multirow[t]{3}{*}{0.8} & \multirow[t]{3}{*}{17.1} \\
\hline & STD & 1.4 & & & 2.1 & & & 0.8 & & \\
\hline & $\% \mathrm{CV}$ & 25.9 & & & 36.2 & & & 14.6 & & \\
\hline \multirow{9}{*}{$\begin{array}{c}\text { I-10 Egan } \\
\text { WC }\end{array}$} & S1 & 6.7 & 0.4 & 6.6 & 7.0 & 0.6 & 8.3 & 6.6 & 0.6 & 8.7 \\
\hline & $\mathrm{S} 2$ & 4.6 & 1.1 & 24.5 & 4.8 & 1.2 & 25.3 & 5.2 & 1.1 & 21.9 \\
\hline & S3 & 8.0 & 0.2 & 2.0 & 8.6 & 0.3 & 3.8 & 7.8 & 0.4 & 5.6 \\
\hline & S4 & 7.4 & 1.6 & 21.6 & 7.9 & 2.0 & 25.1 & 6.3 & 1.1 & 18.3 \\
\hline & S5 & 5.5 & 0.7 & 12.9 & 5.6 & 0.7 & 12.7 & 7.3 & 0.4 & 6.0 \\
\hline & S6 & 6.2 & 0.5 & 8.8 & 6.4 & 0.5 & 8.5 & 6.1 & 0.3 & 4.6 \\
\hline & Avg. & 6.4 & \multirow[t]{3}{*}{0.8} & \multirow[t]{3}{*}{12.7} & 6.7 & \multirow[t]{3}{*}{0.9} & \multirow[t]{3}{*}{14.0} & 6.6 & \multirow[t]{3}{*}{0.7} & \multirow[t]{3}{*}{10.9} \\
\hline & STD & 1.2 & & & 1.4 & & & 0.9 & & \\
\hline & $\% \mathrm{CV}$ & 18.8 & & & 20.9 & & & 13.6 & & \\
\hline Vinton WC & S1 & 7.5 & 0.6 & 7.8 & 8.0 & 0.6 & 7.1 & 4.9 & 0.2 & 4.6 \\
\hline
\end{tabular}

Note:

*PQI takes five readings at each core location.

$\mathrm{n}=$ number of cores; Void = average of air voids; $\mathrm{STD}=$ standard deviation;

$\% \mathrm{CV}=$ percent coefficient of variation 
Table 3. Summary of complex shear modulus results

\begin{tabular}{|c|c|c|c|c|c|c|c|c|c|c|}
\hline & \multicolumn{5}{|c|}{ SGC } & \multicolumn{5}{|c|}{ Core } \\
\hline & \multirow{2}{*}{$\frac{\text { Air Void }}{\%}$} & \multicolumn{4}{|c|}{ Frequency (HZ) } & \multirow{2}{*}{$\frac{\text { Air Void }}{\%}$} & \multicolumn{4}{|c|}{ Frequency (HZ) } \\
\hline & & 10 & 1 & 0.1 & 0.01 & & 10 & 1 & 0.1 & 0.01 \\
\hline \multicolumn{11}{|c|}{ I-10 Egan Binder Course (Complex Shear Modulus, kPa) } \\
\hline Temp. & \multicolumn{10}{|c|}{$48^{\circ} \mathrm{C}$} \\
\hline Average & 5.4 & 164680 & 59308 & 29598 & 20749 & 4.3 & 100849 & 39870 & 23324 & 18227 \\
\hline STD & 0.8 & 26760 & 8757 & 3215 & 1807 & 1.1 & 17387 & 6177 & 3059 & 1789 \\
\hline $\mathrm{CV}(\%)$ & 14 & 16 & 15 & 11 & 9 & 25 & 17 & 15 & 13 & 10 \\
\hline Phase Angle & & 45 & 42 & 35 & 30 & & 49 & 42 & 33 & 28 \\
\hline Temp. & \multicolumn{10}{|c|}{$60^{\circ} \mathrm{C}$} \\
\hline Average & 6.1 & 49702 & 26086 & 18750 & 16416 & 5.5 & 38421 & 21545 & 16383 & 14656 \\
\hline STD & 0.8 & 2902 & 882 & 1022 & 1225 & 1.7 & 6138 & 3428 & 2630 & 2220 \\
\hline $\mathrm{CV}(\%)$ & 14 & 6 & 3 & 5 & 7 & 30 & 16 & 16 & 16 & 15 \\
\hline Phase Angle & & 39 & 31 & 26 & 22 & & 41 & 32 & 26 & 23 \\
\hline \multicolumn{11}{|c|}{ I-10 Egan Wearing Course (Complex Shear Modulus, kPa) } \\
\hline Temp. & \multicolumn{10}{|c|}{$48^{\circ} \mathrm{C}$} \\
\hline Average & 6.1 & 167619 & 67284 & 34919 & 23651 & 6.4 & 101776 & 41775 & 23924 & 17864 \\
\hline STD & 1.1 & 24559 & 9135 & 5469 & 4381 & 1.6 & 9037 & 2907 & 1793 & 1312 \\
\hline $\mathrm{CV}(\%)$ & 18 & 15 & 14 & 16 & 19 & 25 & 9 & 7 & 7 & 7 \\
\hline Phase Angle & & 43 & 41 & 34 & 28 & & 46 & 40 & 32 & 27 \\
\hline Temp. & \multicolumn{10}{|c|}{$60^{\circ} \mathrm{C}$} \\
\hline Average & 5.7 & 69531 & 38642 & 27216 & 23094 & 6.6 & 37009 & 22486 & 17632 & 15972 \\
\hline STD & 2.0 & 15467 & 7098 & 4312 & 3010 & 1.7 & 6546 & 3593 & 2470 & 2118 \\
\hline $\mathrm{CV}(\%)$ & 35 & 22 & 18 & 16 & 13 & 26 & 18 & 16 & 14 & 13 \\
\hline Phase Angle & & 36 & 30 & 24 & 21 & & 37 & 29 & 23 & 20 \\
\hline \multicolumn{11}{|c|}{ I-10 Vinton Wearing Course (Complex Shear Modulus, kPa) } \\
\hline Temp. & \multicolumn{10}{|c|}{$48{ }^{\circ} \mathrm{C}$} \\
\hline Average & 8.0 & 224479 & 88495 & 41194 & 26051 & 8.0 & 158757 & 66262 & 35670 & 24923 \\
\hline STD & 0.8 & 4813 & 1765 & 2177 & 4437 & 0.5 & 916 & 2779 & 2897 & 2998 \\
\hline $\mathrm{CV}(\%)$ & 10 & 2 & 2 & 5 & 17 & 7 & 1 & 4 & 8 & 12 \\
\hline Phase Angle & & 37 & 40 & 36 & 31 & & 41 & 39 & 32 & 27 \\
\hline Temp. & \multicolumn{10}{|c|}{$60{ }^{\circ} \mathrm{C}$} \\
\hline Average & 8.2 & 87058 & 45356 & 29250 & 22825 & 8.5 & 62135 & 35500 & 25044 & 20752 \\
\hline STD & 1.6 & 4747 & 5520 & 4871 & 4012 & 0.4 & 10716 & 8042 & 5730 & 4484 \\
\hline $\mathrm{CV}(\%)$ & 19 & 5 & 12 & 17 & 18 & 4 & 17 & 23 & 23 & 22 \\
\hline Phase Angle & & 37 & 32 & 27 & 23 & & 38 & 31 & 25 & 22 \\
\hline
\end{tabular}




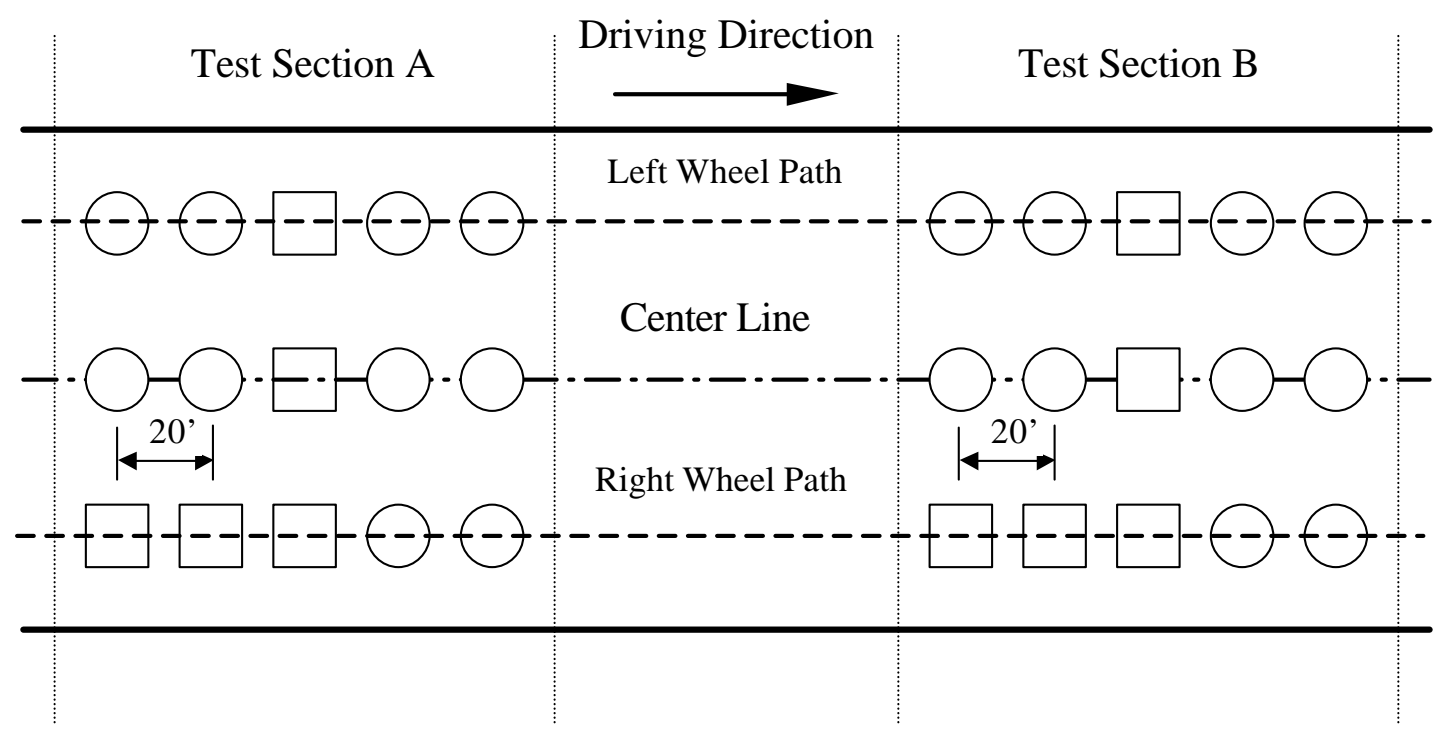

$\bigcirc$--- PQI, LFWD and FWD test points

--- PQI, LFWD, FWD test points and Core locations

(a) NDT Test Layout

Five PQI measurement

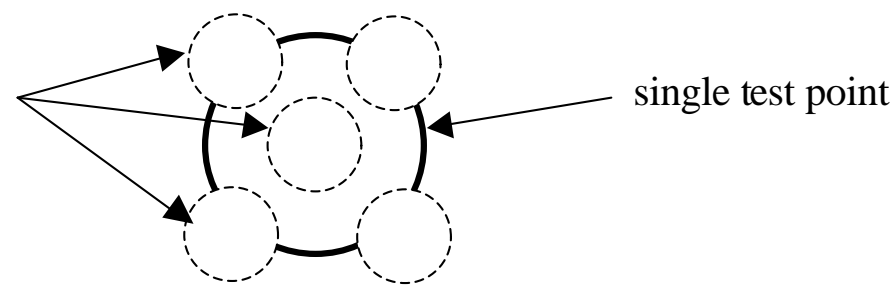

(b) Typical PQI Measurement Configuration

Figure 1: Field test layout and roadway core locations 


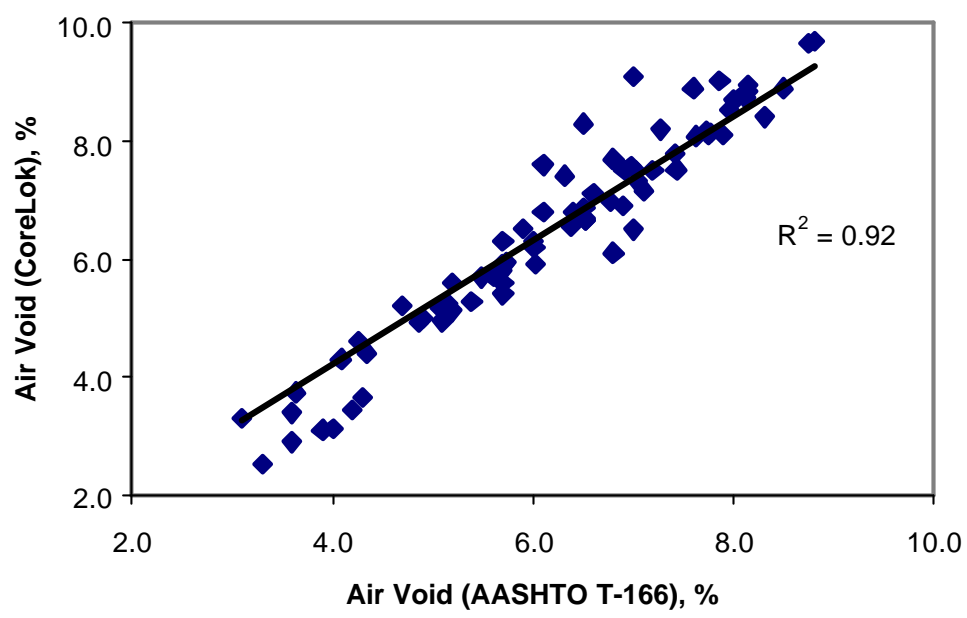

(a)

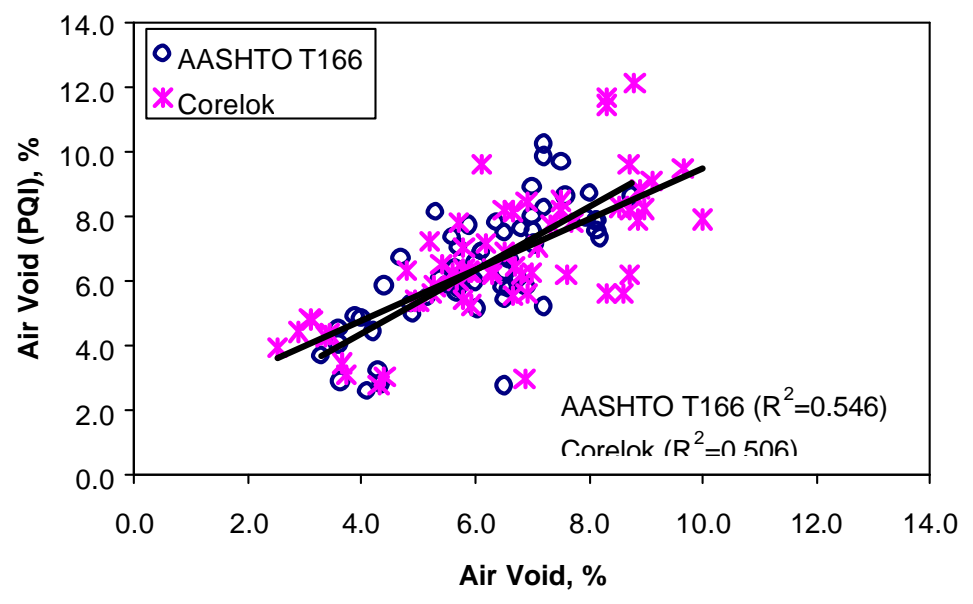

(b)

Figure 2: Air Void Relationship between test methods 


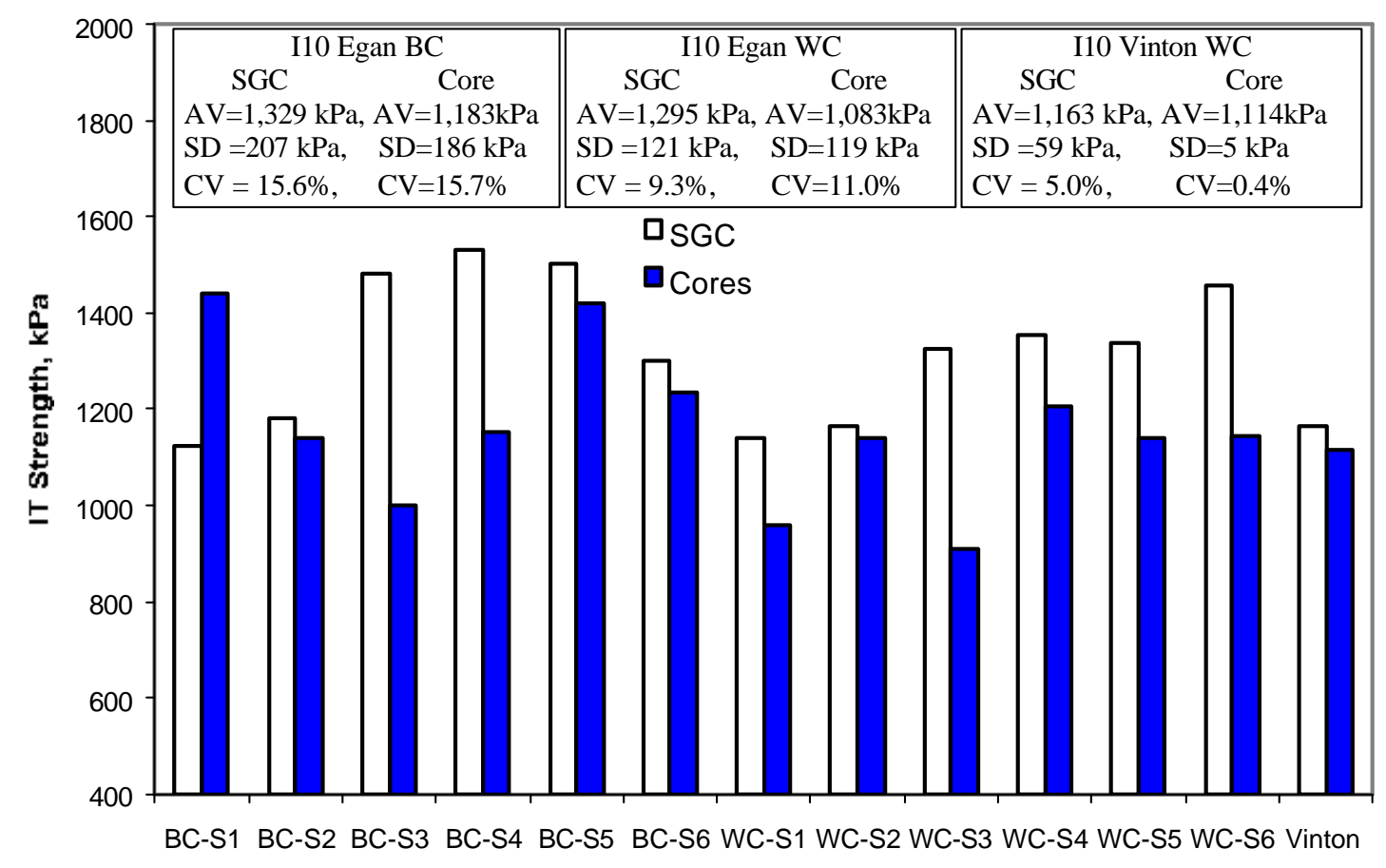

Figure 3: Indirect tensile strength test results

$(\mathrm{AV}=$ Average, $\mathrm{SD}=$ Standard deviation, $\mathrm{CV}=$ percent coefficient of variation)

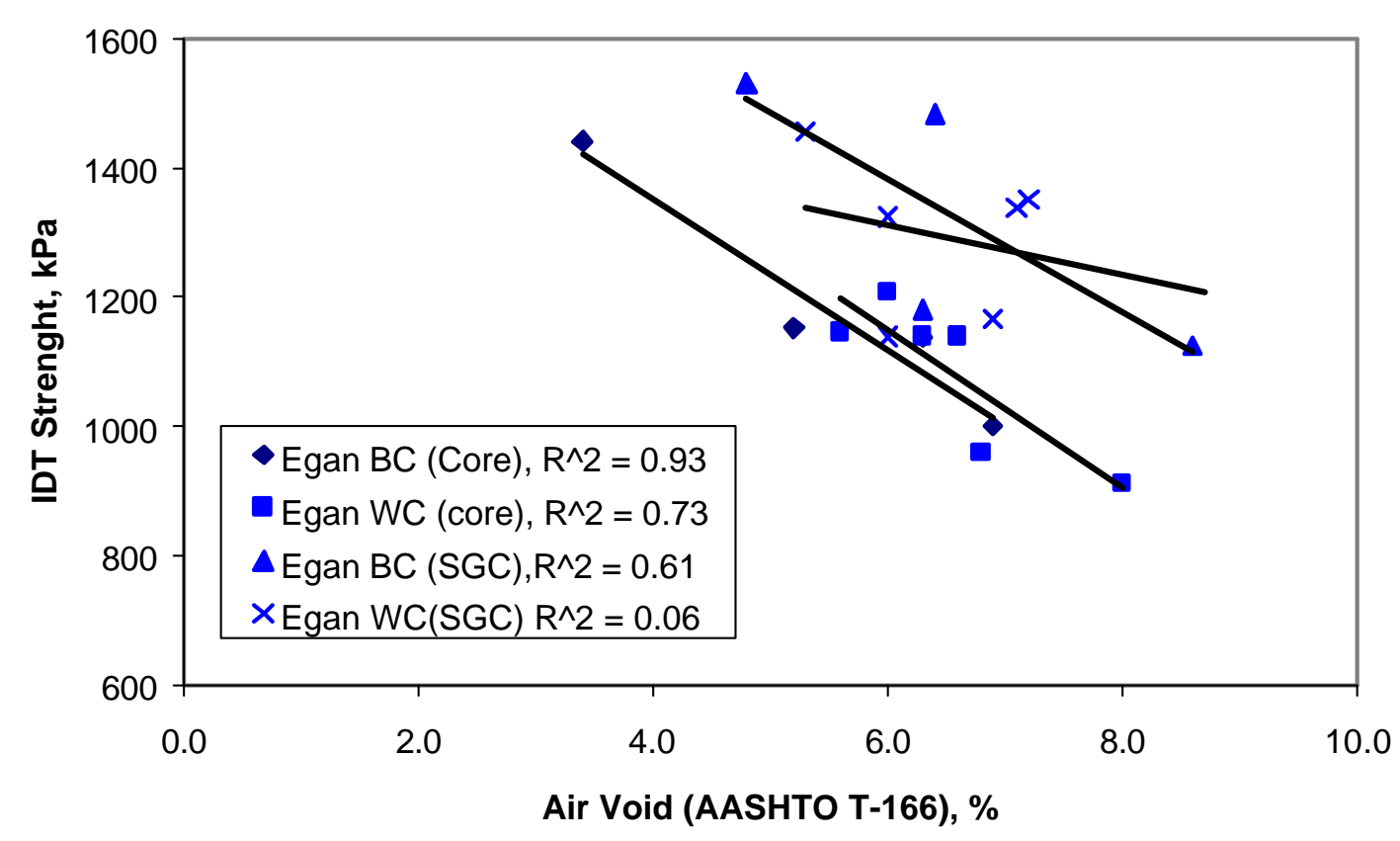

Figure 4: Relationship between IDT strengths and air voids 


\begin{tabular}{|c|c|c|}
\hline I-10 Egan BC & I-10 Egan WC & I-10 Vinton WC \\
\hline SGC Core & Core & SGC Core \\
\hline $\mathrm{AV}=164,680 \mathrm{kPa}, \mathrm{AV}=100,849 \mathrm{kPa}$ & $\mathrm{AV}=167,619 \mathrm{kPa}, \mathrm{AV}=101,776 \mathrm{kPa}$ & $\mathrm{AV}=224,479 \mathrm{kPa}, \mathrm{AV}=158,757 \mathrm{kPa}$ \\
\hline $\begin{array}{ll}\mathrm{SD}=26,760 \mathrm{kPa}, & \mathrm{SD}=17,387 \mathrm{kPa} \\
\mathrm{CV}=16 \%, & \mathrm{CV}=17 \%\end{array}$ & $\begin{array}{ll}\mathrm{SD}=24,559 \mathrm{kPa}, & \mathrm{SD}=9,037 \mathrm{kPa} \\
\mathrm{CV}=15 \%, & \mathrm{CV}=9 \%\end{array}$ & $\begin{array}{ll}\mathrm{SD}=4,813 \mathrm{kPa}, & \mathrm{SD}=916 \mathrm{kPa} \\
\mathrm{CV}=2 \%, & \mathrm{CV}=9 \%\end{array}$ \\
\hline
\end{tabular}

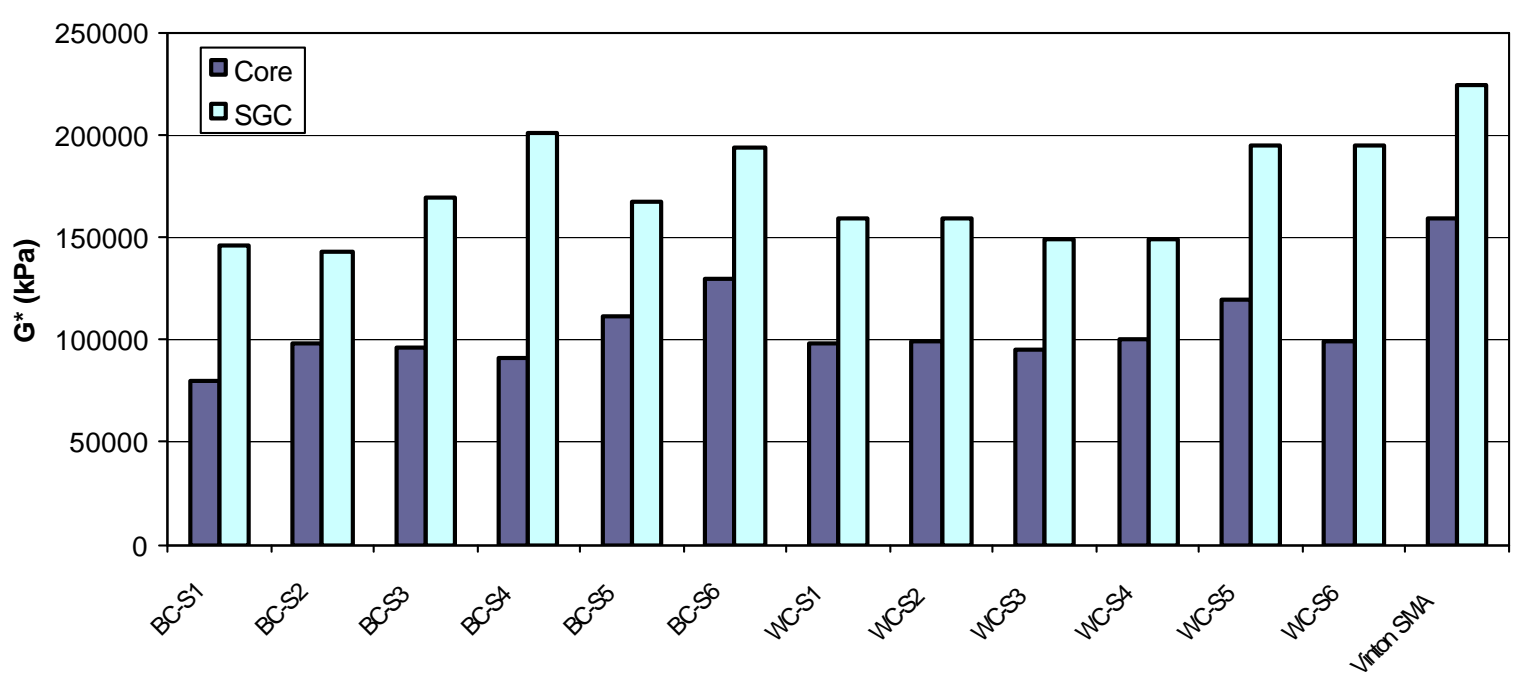

(a)

\begin{tabular}{|c|c|c|}
\hline I-10 Egan BC & I-10 Egan WC & I-10 Vinton WC \\
\hline SGC $\quad$ Core & SGC $\quad$ Core & $\begin{array}{ll}\text { SGC } & \text { Core }\end{array}$ \\
\hline $\mathrm{AV}=49,702 \mathrm{kPa}, \mathrm{AV}=38,421 \mathrm{kPa}$ & $\mathrm{AV}=69,531 \mathrm{kPa}, \mathrm{AV}=37,009 \mathrm{kPa}$ & $\mathrm{AV}=87,058 \mathrm{kPa}, \mathrm{AV}=62,135 \mathrm{kPa}$ \\
\hline $\mathrm{SD}=2,902 \mathrm{kPa}, \quad \mathrm{SD}=6,138 \mathrm{kPa}$ & $\mathrm{SD}=15,467 \mathrm{kPa}, \quad \mathrm{SD}=6,546 \mathrm{kPa}$ & $\mathrm{SD}=4,747 \mathrm{kPa}, \quad \mathrm{SD}=10,716 \mathrm{kPa}$ \\
\hline $\mathrm{CV}=6 \%$ & $\mathrm{CV}=22 \%, \quad \mathrm{CV}=18 \%$ & $\mathrm{CV}=5 \%, \quad \mathrm{CV}=17 \%$ \\
\hline
\end{tabular}

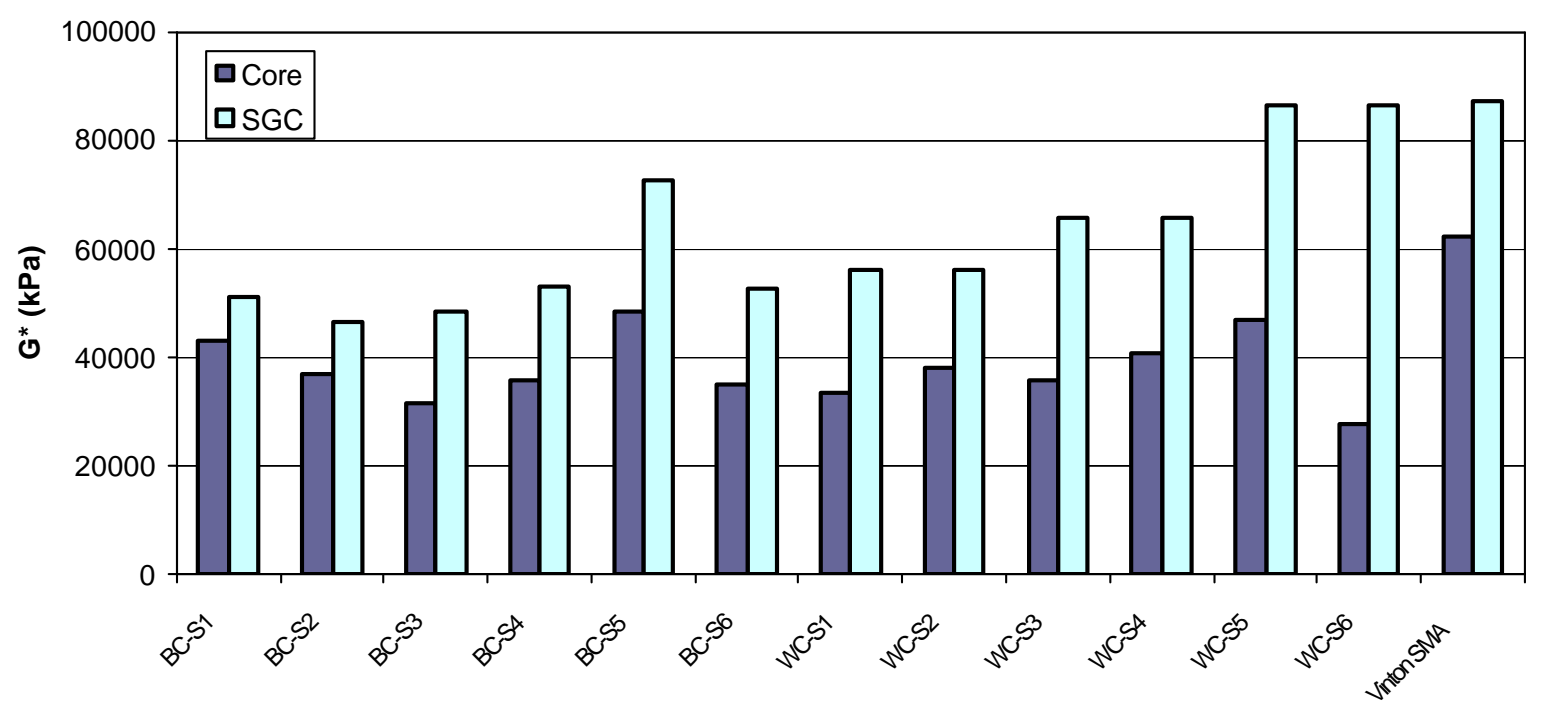

(b)

Figure 5: Results of complex shear modulus $\left(\mathrm{G}^{*}{ }_{10 \mathrm{~Hz}}\right)$ at two test temperatures of (a) $48^{\circ} \mathrm{C}$ (b) $60^{\circ} \mathrm{C}$

( $\mathrm{AV}=$ Average, $\mathrm{SD}=$ Standard deviation, $\mathrm{CV}=$ percent coefficient of variation) 


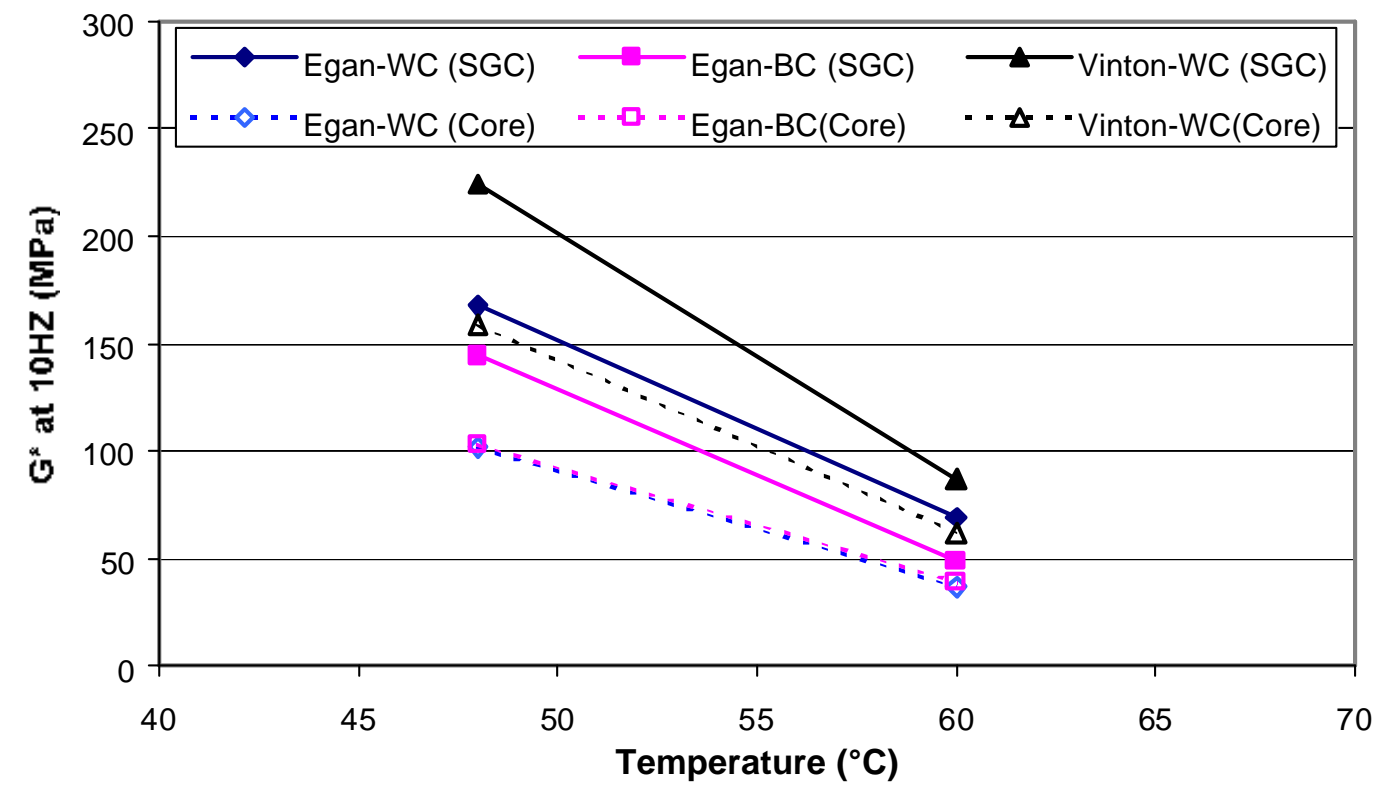

Figure 6(a): Relationship between complex shear modulus $\left(G^{*}{ }_{10 \mathrm{~Hz}}\right)$ and temperatures

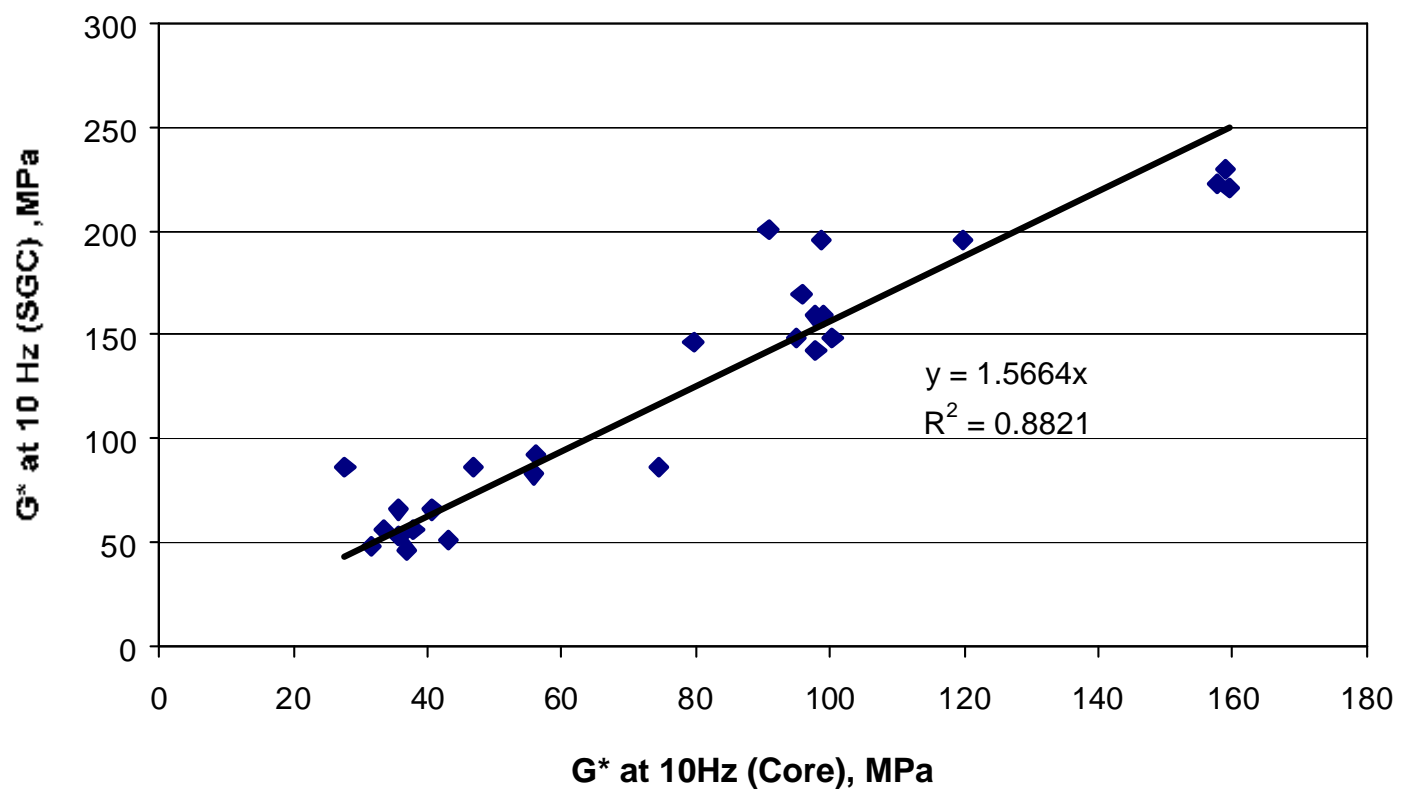

Figure 6(b): Relationship between complex shear moduli of SGC samples and field Cores 


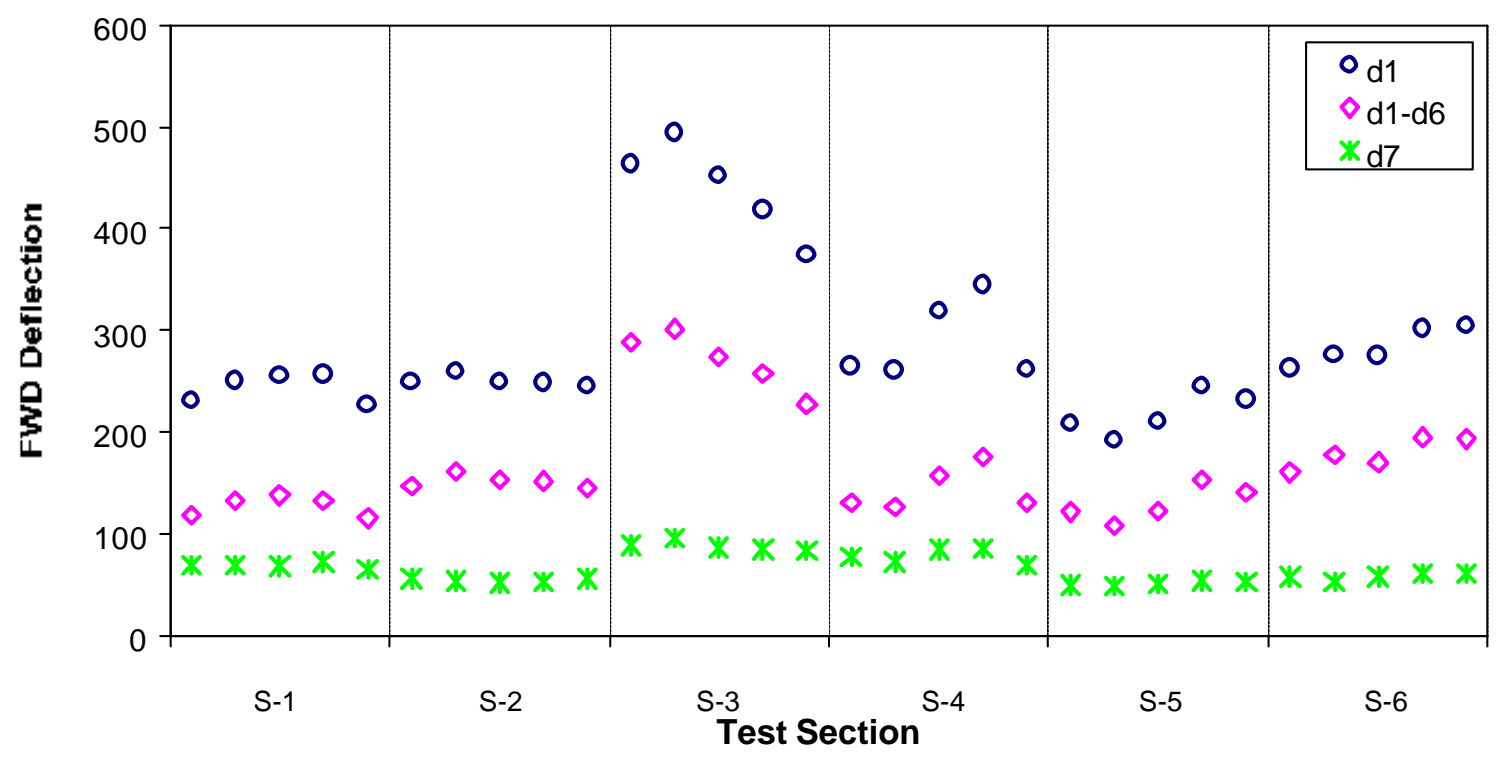

(a)

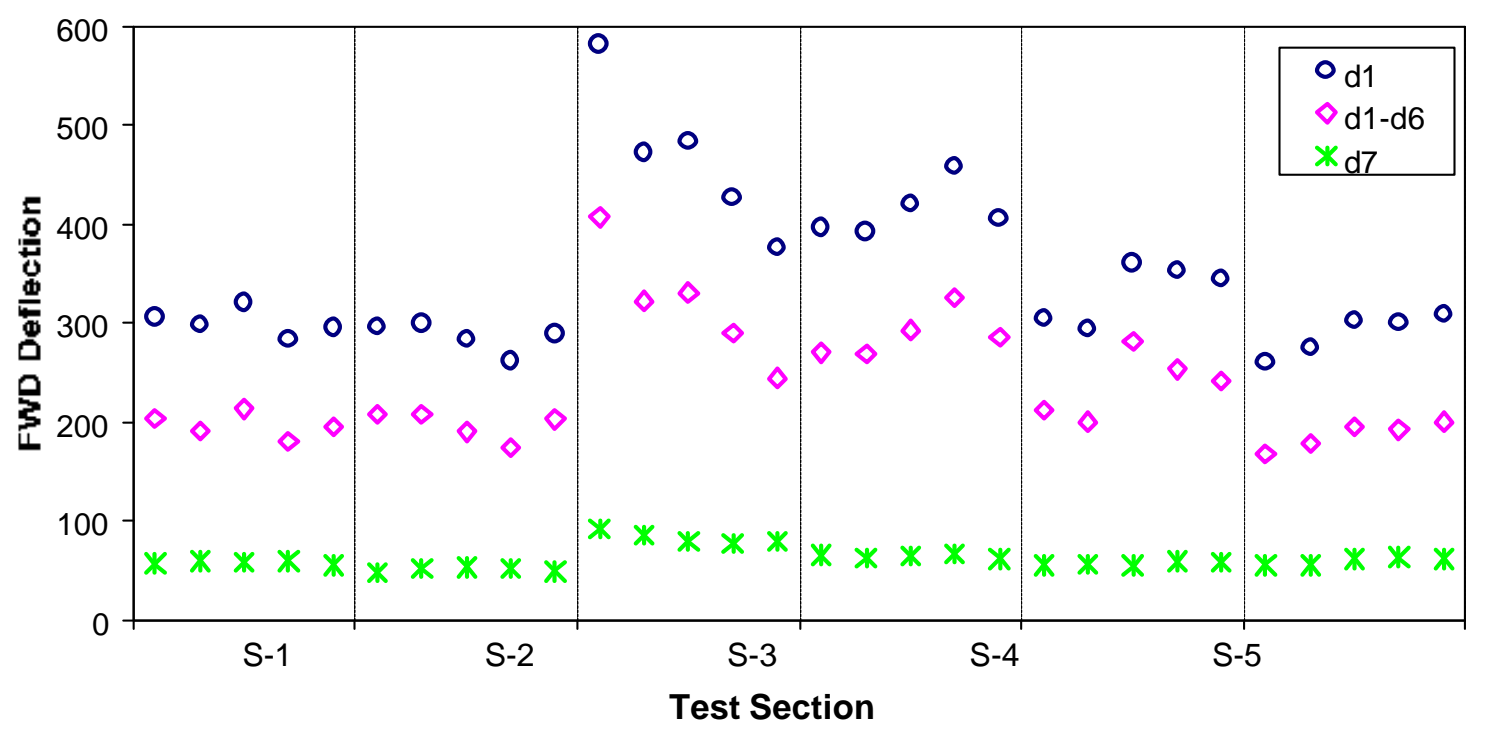

(b)

Figure 7: Results of FWD deflection measurements (a) I-10 Egan Binder Course;

\section{(b) I-10 Egan Wearing Course}




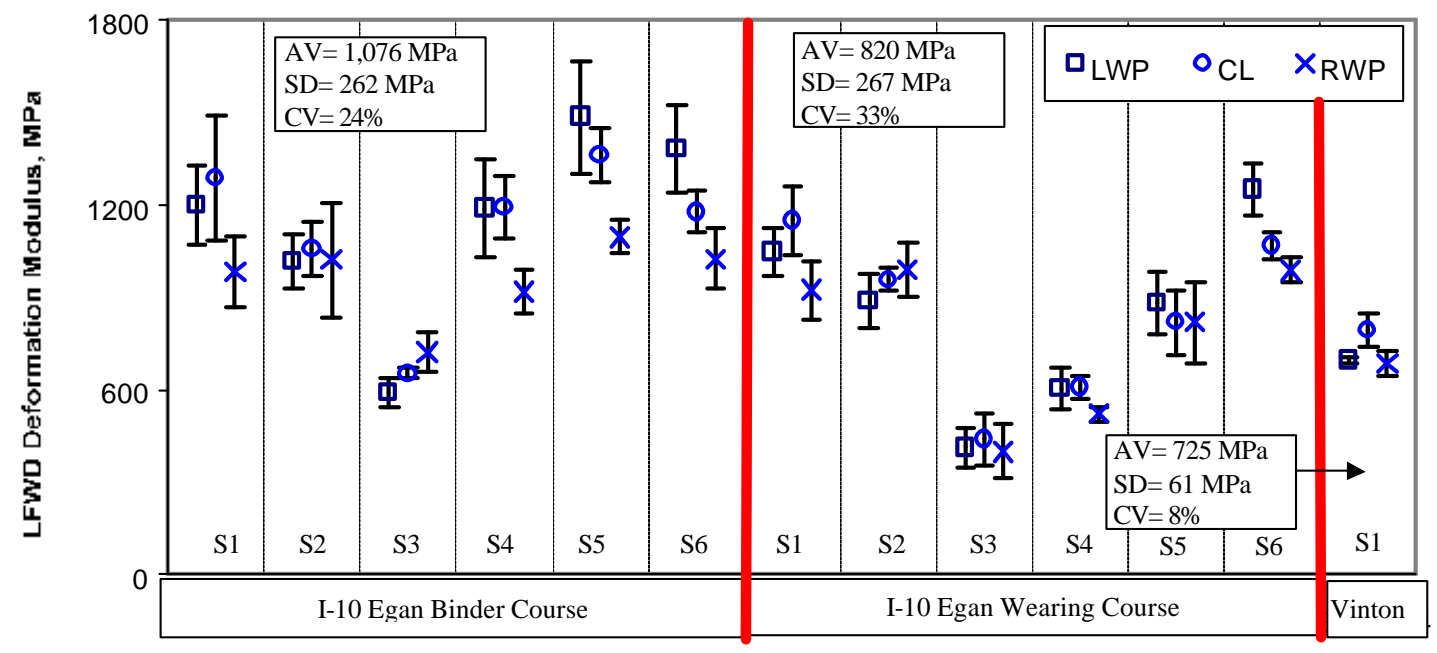

Figure 8: Results of LFWD measurements 


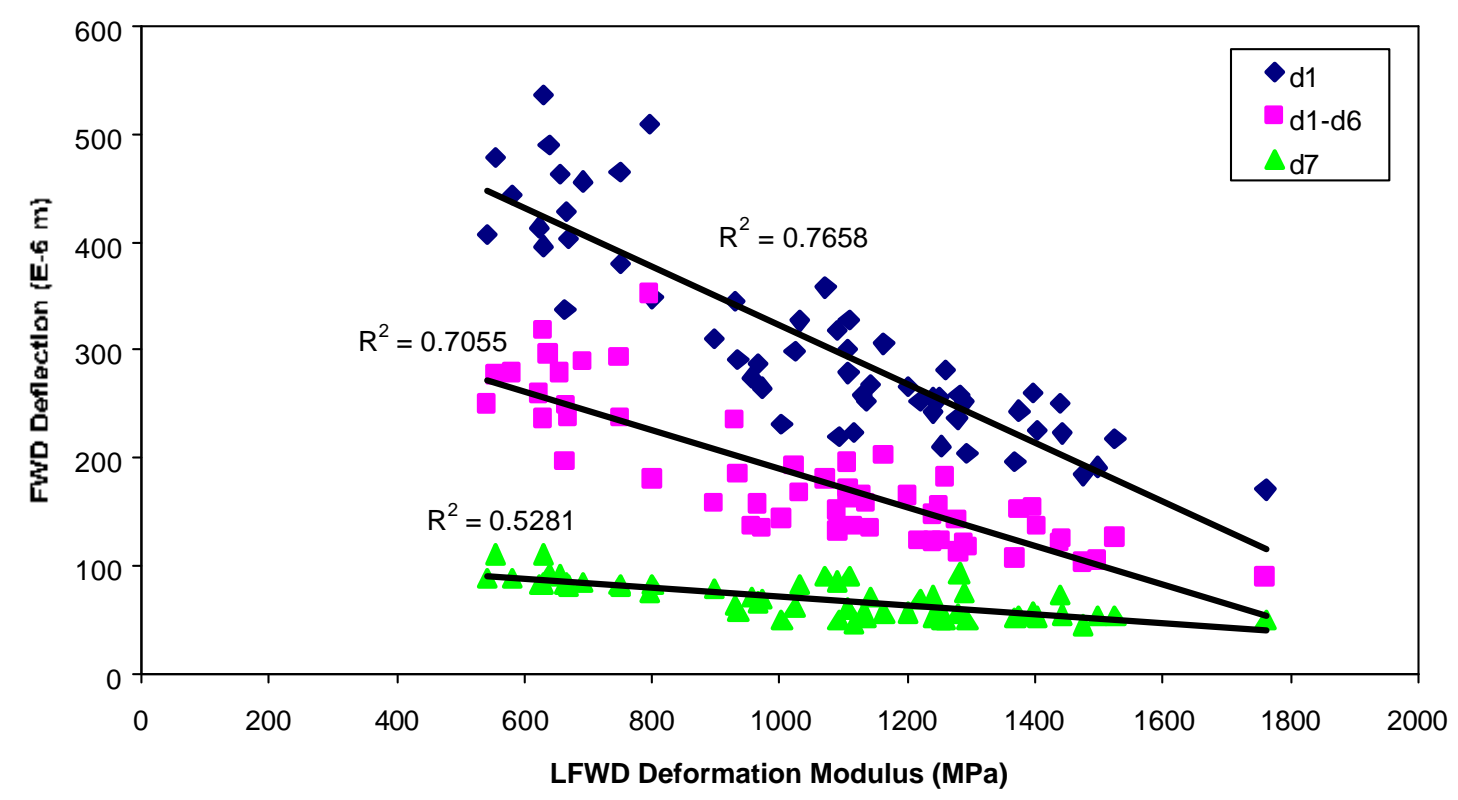

(a)

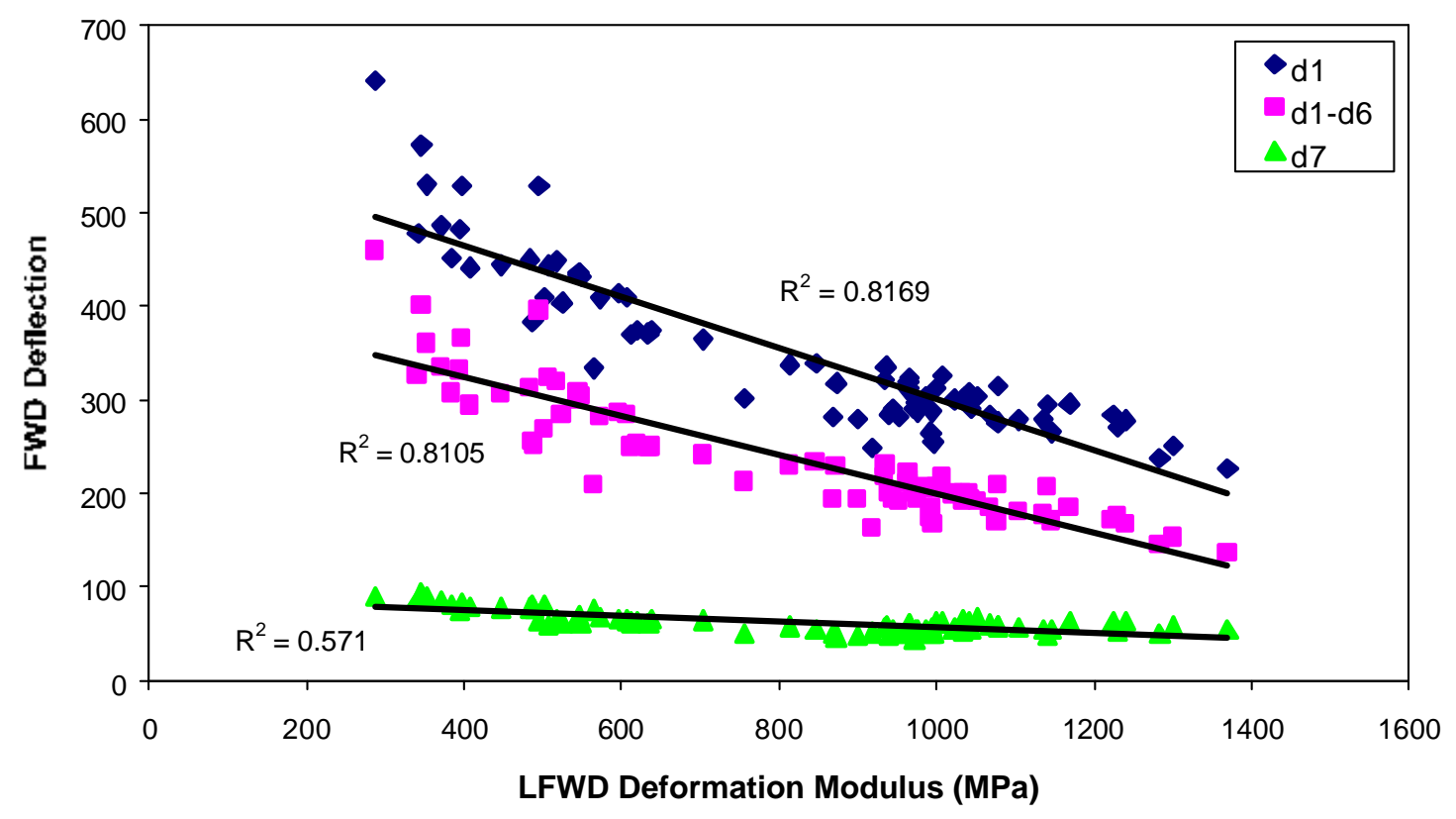

(b)

Figure 9: Relationship between FWD deflection and LFWD deformation modulus (a) I-10 Egan Binder Course; (b) I-10 Egan Wearing Course 